include assured continuity (the same subject is repeated at a follow-on meeting whose Chairman is elected during the current meeting) and funding (part of the participants' fees are ploughed back into the next meeting in a series). There must also be plenty of discussion, and concentration by the Chairman on the scientific programme rather than on organizational aspects which will, in principle, be dealt with by the ERC Secretariat in Strasbourg.

Another guiding principle is the importance of young people. The aim is to have a $20 \%$ participation by junior researchers so that they can become acquainted with more experienced scientists and their work. Supervisors are encouraged to bring along one of their graduate students. However, even if you are young you will still be expected to participate actively.

The question of documentation has not yet been ruled upon. Participation is clearly facilitated, especially for sought-after experts, if one does do not need to submit texts for the preparation of proceedings. Participants are also willing to discuss topics more freely if there is no formal report. However, many organizations demand some form of proof, especially from younger scientists, that a contribution has been made; proceedings often satisfy this requirement.

\section{Organization}

ERC's grew out of a proposal by an ESF Working Group (chaired by Professor Claude Fréjacques) that was accepted by the ESF Council last year. Contributions by ESF Member Organizations, the Commission of the European Communities and other sources to a special Seed Fund have provided financing for an 18 month pilot phase lasting from mid 1990 to the end of 1991. A total of six series for 1990 will start after September 1990. The deadline for proposals for 1991 has passed and the programme for 1991 comprising about 25 meetings will be announced in October 1990.

Of the six ERC's slated for 1990, two concern physics. They are the ERC on Quantum Optics, chaired by Professor $\mathrm{H}$. Walther, the previous Chairman of the EPS Quantum Optics Division, to be held in Davos, Switzerland on 1-5 October 1990. The other is the ERC on Colloids and Interfaces: Polyelectrolytes, at Maria Laach (near Koblenz), chaired by Professor H. Hofmann on 3-7 September 1990. Attendance applications forms and other details are available from the ERC Secretariat in Strasbourg (see below for the address) but please note that the attendance deadlines for these two meetings have passed.

For 1991, the EPS Working Group on ERC will have aimed to have submitted six proposals to the ERC Steering Committee. To meet with the current ERC policy, which is to encourage in the early stages concentration on research in the physical sciences, these suggestions were shortlisted from among those put forward by the Chairmen of Divisions.

In partnership with the CEC, the ESF through the ERC Steering Committee is aiming for about 45 meetings in 1992 involving up to 3000 scientists from all over the world. At least $6-8$ of these meetings will be in physics; several others may require a significant input from physics, both in evaluating proposals and helping to develop the scientific programme.

The ESF is presently negotiating with the CEC for a partnership agreement in the running of a full, five year programme. CEC funding may come from a programme within the new Framework Programme for science and technology such as RESEARCHERS' EUROPE that focuses upon human resources. The plan is to seek CEC finance for 100 meetings each year (with at least 10 in physics) for 1993 and beyond.

\section{Proposals}

Physicists wishing to submit a proposal for 1992 at the earliest are asked to liase with the Chairman of the appropriate EPS Division who will ultimately be responsible for assuring the continuing high quality of a specific series. Proposals should be submitted either to the EPS Working Group on ERC at the EPS Secretariat, Geneva or to the ERC Secretariat before the end of March the year before the meeting is to be held (i.e. by 31 March 1991 for 1992).

One is advised to make a fairly detailed proposal that spells out the scientific programme (its objectives and why it is important), together with proposed speakers and a preliminary budget giving indications of expenses for speakers etc. The Chairman of a meeting will receive a cash grant up to a specified limit with which invited speakers can be paid provided a budget is submitted.

The aim is that the ERC Secretariat will ultimately handle all aspects other than the programme. However, this represents a formidable task so EPS members with experience in running the Study Conferences are urged to make their own attractive proposals for both the location and accommodation.

Hence, for the time being at any rate, proposals covering really top-class topics will clearly have a better chance if an accessible site offering good value accommodation is proposed. In any event, it is important to base the proposal upon the Guidelines to Chairpersons (and eventually upon the guidelines for proposals which are being drafted). These are (will be) available from:

Dr. Josip Hendekovic

Executive Secretary, ERC Programme,

European Science Foundation,

1, quai Lezay-Marnésia,

F-67000 Strasbourg.

TI/Fx: ++33() $88356063 /++33() 88370532$.

\title{
Budapest To Be Boosted
}

It is perhaps unnecessary to repeat that colleagues in eastern Europe need to be helped and fully integrated into all aspects of the physics community's activities, especially now that their national societies are increasingly responsible for their own affairs. The Executive Committee has been analyzing all the options and their decision is straightforward: expand the EPS Supplementary Secretariat in Budapest by transferring as much as possible of the Society's administrative work.

Professor Ricci, the President, has informed Council Members of the overall decision. It will now be presented to the General Meeting of Members on 5 September 1990 which takes place during the General Conference in Amsterdam. Final details of the financial and managerial plans will be submitted to the Executive Committee for approval a few days beforehand.

The decision is based on an extensive series of meetings, reports and working visits by both the Executive Committee and the Task Force set up after the last Countil meeting in Uppsala to recommend ways to achieve a balanced budget in 1991. The Task Force chaired by the Treasurer, $\mathrm{Ph}$. Choquard, took the initiative to examine in detail options based upon redeploying resources in the east. In reporting its findings the Task Force aimed to ensure that the Executive Committee could exercise a wider responsibility in formulating a plan that combined effective help for eastern colleagues with reduced expenditures.

As Professor Ricci pointed out in his letter to Council members, reinforcing the Budapest Secretariat comes at an appropriate time. EPS is presently consolidating several important initiatives, contacts and working schemes in the western part of Europe. Attention can now be focussed on ways to help in the east by creating and extending similar arrangements.

It is inappropriate to anticipate details of the Executive Committee's final working scheme for strengthening the Supplementary Secretariat. One possibility being discussed is to concentrate the Executive Secretary's activities in Budapest for 2-3 years with the longer term aim of building up a solid administrative office. Both are now entirely feasible because the standards of communications and facilities in Budapest are rapidly approaching those found in the west.

EPS publication activities including the Editorial Office of Europhysics Letters and the production of Europhysics News and Europhysics Conference Abstracts will continue at the Main Secretariat in Geneva, together with initiatives involving Associate Members. 